\title{
SPECTRAL AND PHOTOMETRIC CHARACTERISTICS OF MID-LATITUDE AURORA DURING THE MAGNETIC STORM OF MARCH 17, 2015
}

\begin{abstract}
A.V. Mikhalev
Institute of Solar-Terrestrial Physics SB RAS, Irkutsk,Russia,mikhalev@iszf.irk.ru
\end{abstract}

\section{A.B. Beletsky}

Institute of Solar-Terrestrial Physics SB RAS, Irkutsk,Russia,beletsky@iszf.irk.ru

\section{R.V. Vasilyev}

Institute of Solar-Terrestrial Physics SB RAS, Irkutsk, Russia,roman_vasilyev@iszf.irk.ru

\section{G.A. Zherebtsov}

Institute of Solar-Terrestrial Physics SB RAS, Irkutsk,Russia,gaz@iszf.irk.ru

\author{
S.V. Podlesny \\ Institute of Solar-Terrestrial Physics SB RAS, \\ Irkutsk, Russia, step8907@mail.ru
}

\author{
M.A. Tashchilin \\ Institute of Solar-Terrestrial Physics SB RAS, \\ Irkutsk, Russia,miketash@iszf.irk.ru

\section{M.F. Artamonov} \\ Institute of Solar-Terrestrial Physics SB RAS, \\ Irkutsk, Russia,artamonov.maksim@iszf.irk.ru
}

\begin{abstract}
We study the spatiotemporal dynamics of mid-latitude aurora from observations in the south of Eastern Siberia during St. Patrick's severe geomagnetic storm on March 17, 2015. We perform a morphological analysis of characteristics of the observed auroras. A preliminary conclusion is drawn that the analyzed event is the result of the manifestation of mid-latitude auroras of two types (type "d" and SAR arc) and ordinary aurora observed at the northern horizon. The maximum intensity
\end{abstract}

\section{INTRODUCTION}

Mid-latitude auroras (MLA) are a relatively rare geophysical phenomenon. According to [Krakovetsky et al., 1989], the probability of MLA observation in the Northern Hemisphere is five cases per year at geographical latitudes $55^{\circ}-60^{\circ} \mathrm{N}$; one, at $50^{\circ}-55^{\circ} \mathrm{N} ; 0.1$, at $40^{\circ}-50^{\circ} \mathrm{N}$. The main dominant emission of MLA is the forbidden $630.0 \mathrm{~nm}$ atomic oxygen [OI] line whose intensity depends on the degree of development of the ring current (Dst index) during a magnetic storm (MS) [Truttse, 1973; Rassoul et al,. 1992; Mikhalev et al., 2004]. The minimum Dst index $\left(D s t_{\min }\right)$ for the March 17, $2015 \mathrm{MS}$ is $-222 \mathrm{nT}$ [http://wdc.kugi.kyoto-u.ac.jp/dst_realtime]. This, according to [Gonzalez et al., 1999], allows us to assign this storm to extreme MS. The last MS with $D s t_{\min }<-220 \mathrm{nT}$ occurred on May 15, 2005 in solar cycle 23. Thus, the March 17, 2015 MS is one of the strongest (by Dst) magnetic storms of solar cycle 24 .

This paper reports the results of MLA observations made with a complex of optical instruments in the south of Eastern Siberia during St. Patrick's geomagnetic storm on March 17, 2015. We perform a preliminary morphological analysis of characteristics of the observed MLA, without detailed, with some exceptions, comparison with ionospheric, magnetospheric, satellite data and models. Such a comparison that is undoubtedly of great interest may be a subject for further research.

\section{EQUIPMENT AND$$
\text { OBSERVATIONAL METHOD }
$$

The observations have been made at the ISTP SB RAS Geophysical Observatory (GO) $\left(52^{\circ} \mathrm{N}, 103^{\circ} \mathrm{E}\right)$, of the dominant emission [OI] at $630.0 \mathrm{~nm}(\sim 14 \mathrm{kR})$ allows this mid-latitude aurora to be attributed to the extreme auroras occurring in mid-latitudes, which is second only to the November 20, 2003 superstorm ( 19 kR).

Keywords: geomagnetic storm, mid-latitude aurora, spectrum of mid-latitude aurora, 557.7 and $630.0 \mathrm{~nm}$ emissions.

located in the Tunka valley (Tory) in the south of Eastern Siberia. During the observation of the March 17, 2015 magnetic storm, the complex of optical instruments included two spectrographs, a wide-angle color camera, an all-sky camera at $630 \mathrm{~nm}$, and a FabryPerot interferometer $(630 \mathrm{~nm})$. All the optical instruments operated in automatic mode.

Spectrographs. A patrol spectrograph with low spectral resolution is designed to detect viewing spectra of nightglow [http://atmos.iszf.irk.ru/ru/data/spectr]. During the March 17, 2015 MS, the spectrograph was oriented northward with a $\sim 23^{\circ}$ elevation of the optical axis above the horizon; the exposure time was $260 \mathrm{~s}$. The absolute calibration of the patrol spectrograph is described by Mikhalev [2018]. The Shamrock SR-303I spectrograph [Beletsky et al., 2016] was also oriented northward with a $\sim 30^{\circ}$ elevation of the optical axis above the horizon. Measurements have been made in series of 30 frames with $1 \mathrm{~s}$ exposure time (frames of each series are summed up). The full operating spectral band of the Shamrock SR-303I spectrograph is $492-896 \mathrm{~nm}$.

The wide-angle color camera is designed to detect and examine spatio-temporal variations of nightglow and to monitor atmospheric transparency [http://atmos.iszf. irk.ru/ru/data/color]. The camera was focused on the northern sky, on the celestial pole. Its angular field of view is $\sim 85^{\circ}$. The exposure time is $300 \mathrm{~s}$.

The all-sky camera KEO Sentinel is designed to record spatial patterns of $630 \mathrm{~nm}$ emission intensity (an emission height is $180-300 \mathrm{~km}$ ). The half-width of the interference filter is $\sim 2 \mathrm{~nm}$. The viewing direction is zenith, the field of view is $145^{\circ}$, the exposure time is $30 \mathrm{~s}$ 
[http://atmos.iszf.irk.ru/ru/data/keo].

Keo Scientific's Fabry-Perot interferometer. Characteristics of the Fabry-Perot interferometer (FPI) in hand are discussed by Shiokawa et al. [2012]. The analysis of interferograms to obtain variations in line intensities is based on the method set forth by Harding et al. [2014]; and Vasilyev et al. [2017] give details of adaptation of this method for a particular device and observing program in use. During the observation of the magnetic storm, FPI worked in the mode of patrol survey of five directions - cardinal directions and zenith.

\section{OBSERVATIONAL RESULTS AND DISCUSSION}

The March 17, 2015 geomagnetic storm, named according to the day of its onset St. Patrick's storm, is one of the severest geomagnetic storms of solar cycle 24; and by the Dst index, the most powerful storm in this cycle. The geomagnetic effect of this storm is due to the superposition of two consecutive storms [Kamide, Kusano, 2015].

Features of the spectral composition of the March 17, 2015 MS It is believed that in MLA spectra, lines and bands can appear or intensify which are typical of both mid-latitude airglow and auroras, in particular, 557.7 and $630.0 \mathrm{~nm}$ atomic oxygen [OI] lines, $520 \mathrm{~nm}$ nitrogen [NI] line, bands of the first negative system $1 \mathrm{~N}_{2}{ }^{+}$ 391.4, 427.8, and $470.9 \mathrm{~nm}$, etc. In terms of intensities and ratio of dominant emissions, MLA falls into different types [Rassoul et al., 1993].

Figure 1 shows a typical spectrum in the 500-700 $\mathrm{nm}$ wavelength range, recorded by the Shamrock SR303I spectrograph during MS.
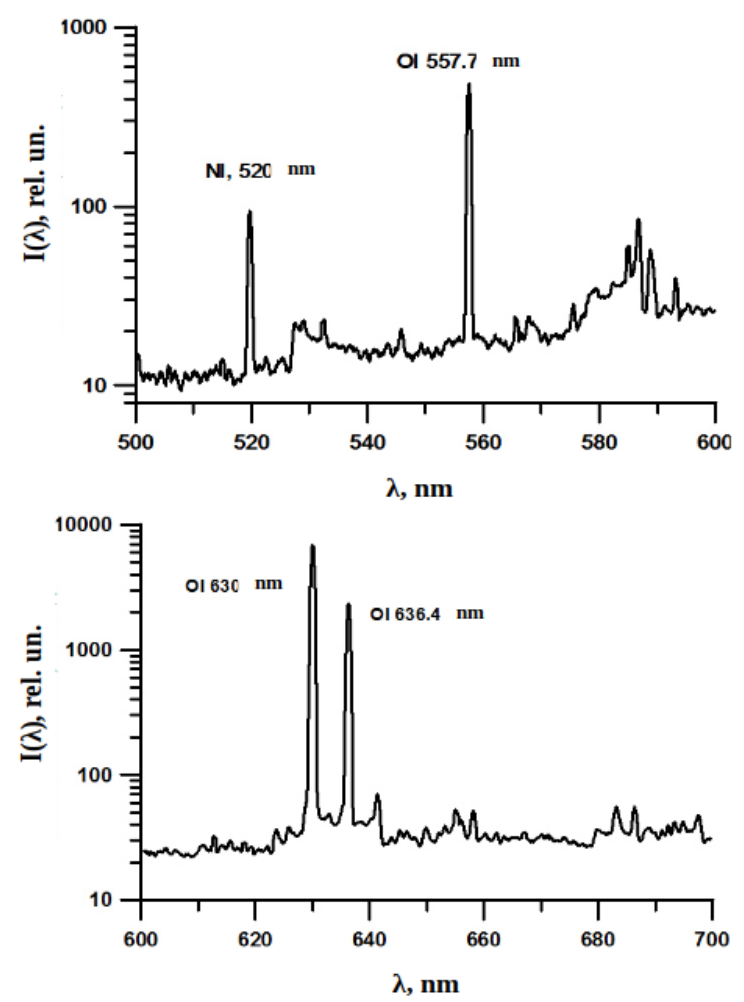

Figure 1. MLA spectrum in the 500-700 nm wavelength range, recorded by the Shamrock SR-303I spectrograph during the March 17, 2015 MS
Figure 2 presents the dynamics of the 630.0 and $557.7 \mathrm{~nm}$ dominant emissions of March 17, 2015 and their ratio, derived from patrol spectrograph observations. For comparison, the Figure depicts the behavior of the Dst index over the same period.

According to GO observations of MLA during severe MS in previous solar cycles [Mikhalev et al., 2004, 2005], it was concluded that depending on the level of geomagnetic activity and magnetic storm phase MLA can be assigned to different types: «d» (with the 630.0 $\mathrm{nm}$ dominant emission), SAR arc $(630.0 \mathrm{~nm})$, and aurora (557.7 and $630.0 \mathrm{~nm})$. MLA of these types differ in spectral composition, intensities of dominant emissions, and detection probability at night, thus reflecting the current state and dynamics of magnetosphericionospheric structures and their projections on heights of the upper atmosphere.

As derived from GO optical observations over the period 1991-2017, by maximum intensity of the $630.0 \mathrm{~nm}$ dominant emission ( 14 kR) the MLA of interest is second only to the MLA occurring during the November 20, 2003 superstorm with $D s t_{\min }=-465 \mathrm{nT}(\sim 19 \mathrm{kR})$. During other strong MS with a lower Dst index, intensities of the $630.0 \mathrm{~nm}$ dominant emission do not exceed 10.5 kR (e.g., during the March 24, $1991 \mathrm{MS}, D_{s t_{\min }=-}$ 281; during the April 6, $2000 \mathrm{MS}, D s t_{\min }=-287$; during October 30, $2003 \mathrm{MS}, D s t_{\min }=-401$ [Mikhalev et al., 2005]). Other features atypical of the MLA previously observed at GO are the lack of dependence of the $630.0 \mathrm{~nm}$ emission on Dst at night and the presence of pronounced bursts of the $630.0 \mathrm{~nm}$ emission with characteristic durations of $\sim 1 \mathrm{hr}$, more typical of substorm activity in subauroral and auroral latitudes. In the emission spectrum of the analyzed MLA, in addition to the 557.7 and $630.0 \mathrm{~nm}$ dominant auroral emissions also typical of the mid-latitude atmospheric emission, we recorded the $520 \mathrm{~nm}$ [NI] emission and the $\mathrm{N}_{2}^{+} 586.7 \mathrm{~nm}$ band. Thus, by its spectral characteristics the MLA observed in the northern sky may be assigned to the type «d» with manifestations of substorm activity superimposed in separate time intervals.



Figure 2. Intensities of the 630.0 and $557.7 \mathrm{~nm}$ emissions, and Dst variations during the March 17, 2015 magnetic storm 
Photometric aspect observations made with the color wide-angle camera in RGB channels. As noted above, the color camera during the March 17, 2015 MS was pointed at the north. Figure 3 presents images of the northern sky in R, $\mathrm{G}$, and B channels, captured by the camera at 15:22 UT.

The diffuse brightness distributions (Figure 3) occupying most of the northern sky in the $\mathrm{R}$ channel and localized near the horizon in the $\mathrm{G}$ channel lasted almost throughout the night on March 17, 2015. Using spectral characteristics of R, G, and B channels and features of the spectral composition of the upper atmosphere emission during MLA (Figures 1, 2), within certain assumptions we can estimate the southern boundary of precipitation during MS under study. Thus, Podlesny, Mikhalev [2015] and Mikhalev et al. [2016] have shown that disturbances in the $\mathrm{R}$ channel of the color camera during the March 17, 2015 MS are largely caused by increased intensity of the $630.0 \mathrm{~nm}$ emission. Suppose that the disturbance in the $\mathrm{G}$ channel is similarly related to the enhanced $557.7 \mathrm{~nm}$ emission, then spatio-temporal variations in brightnesses of $\mathrm{R}$ and $\mathrm{G}$ images may be caused by variations in the $630.0 \mathrm{~nm}$ and $557.7 \mathrm{~nm}$ emission intensities respectively. It is believed that the $557.7 \mathrm{~nm}$ emission with characteristic heights $\sim 90-110 \mathrm{~km}$ is dominant in aurora [Omholt, 1974]. Thus, knowing the angular height of the maximum emission near the horizon in the $\mathrm{G}$ channel, which in our case is $\sim 8^{\circ}-10^{\circ}$, we can estimate the distance to the emission region. Referring to the obtained data, the distance to the visible precipitation zone can be estimated as $\sim 530-785 \mathrm{~km}$. This corresponds to the displacement northward of the observation point by $\sim 5^{\circ}-7^{\circ}$ from the ISTP SB RAS GO geomagnetic latitude $\left(47.9^{\circ} \mathrm{N}\right)$.

MLA images captured by the color camera in the $\mathrm{R}$ channel have much larger angular sizes than those taken in the $\mathrm{G}$ channel. Besides the region coinciding with airglow

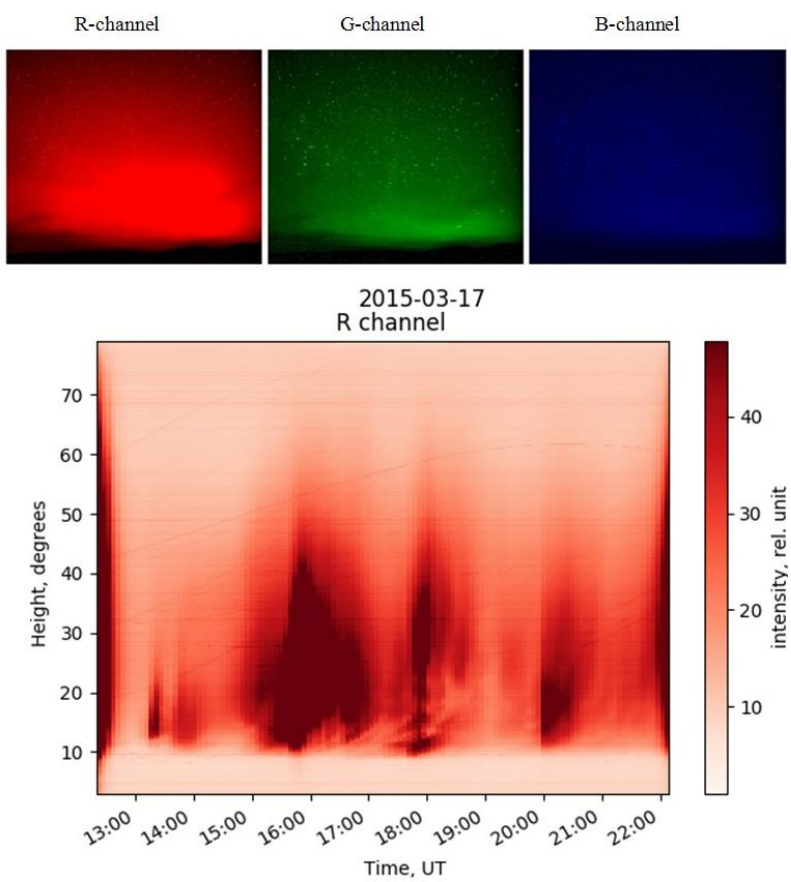

Figure 3. Images of the northern sky in the R, G, and B channels, captured by the color camera at ISTP SB RAS GO at 15:22:30 UT (a); keogram of MLA in the R channel (b) in the $\mathrm{G}$ channel at angular heights $8^{\circ}-10^{\circ}$, there is an intense airglow in the angular range $\sim 10^{\circ}-35^{\circ}$ above the horizon with a peak intensity of $\sim 22^{\circ}$.

As already mentioned, the disturbances in the $\mathrm{R}$ channel of the color camera during the March 17, 2015 MS may be associated with increased intensity of the $630.0 \mathrm{~nm}$ emission [Podlesny, Mikhalev, 2015; Mikhalev et al., 2016]. In this case, assuming that the $630.0 \mathrm{~nm}$ emission region coincides with the $557.7 \mathrm{~nm}$ emission region with an estimated range $\sim 530-785 \mathrm{~km}$ from the observation point, we can assess the vertical distribution of the $630.0 \mathrm{~nm}$ emission during MLA. Thus, the maximum $630.0 \mathrm{~nm}$ emission is at heights $\sim 200-300 \mathrm{~km}$, and the upper boundary is at $350-550$ $\mathrm{km}$. The large height of the maximum $630.0 \mathrm{~nm}$ emission and the vertical extent of MLA in the $630.0 \mathrm{~nm}$ emission, as largely the diffuse nature of airglow, allows us to assign this aurora by color characteristics to red auroras of type «d» (red color of the total aurora is typical of subauroral auroras, which are characterized by large (hundreds of kilometers) heights). At the same time, in some short intervals of observations (e.g., at 16:30-18:30 UT with increasing $557.7 \mathrm{~nm}$ emission), this aurora can be qualified as a type "a" aurora (red color in the upper part of the aurora and prevailing green color in the lower part). It is believed that a direct source of the $630.0 \mathrm{~nm}$ emission (the ${ }^{1} \mathrm{D}$ level) in type "d" MLA is electrons with energies $\sim 10-1000 \mathrm{eV}$ [Rassoul et al., 1993]. Thus, data from the color camera can supplement spectral observations, for example, suggest that by its color characteristics the March 17, 2015 MLA can be attributed to the red type "d" aurora and, in some intervals, to the type "a" aurora; they can also enable us to estimate the distance to the equatorial boundary of the detected MLA, which is $~ 530-785 \mathrm{~km}$, being equivalent to geomagnetic latitudes $\sim 47^{\circ}-49^{\circ}$.

Photometric observations in the $630.0 \mathrm{~nm}$ emission with the all-sky camera KEO. The angular field of view of the all-sky camera KEO is $\sim 145^{\circ}$. When pointed at the zenith, it captures an image at angular heights of $>18.5^{\circ}$ above the horizon, thus allowing us to compare the dynamics of brightnesses of images in a northerly direction with spectrograph data. In Figure 4 are images in the $630 \mathrm{~nm}$ emission captured by this camera at 12:53, 15:30, 16:39, 19:00, and 21:08 UT versus the dynamics of the $630 \mathrm{~nm}$ emission obtained by the patrol spectrograph.

The analysis of the images in the $630.0 \mathrm{~nm}$ emission (Figure 4) allows us to identify several specific development stages in the analyzed MLA. The first stage (12:1513:00 UT) features afterdusk undisturbed conditions.

In Figure 4, to this stage corresponds the first left image (the near-horizon brightness enhancement in the form of a circle is due to the Van Rine effect, caused by an increase in the optical thickness of the luminescent layer toward the horizon). The second stage ( 13:0013:30 UT) is associated with the appearance of a diffuse spot near the northern horizon, which moves along the horizon. During the next stage ( 13:45-15:30 UT), the second layer of weak airglow is formed (equatorward of the diffuse spot) which moves slowly to the equator. From 15:30 UT and to the end of observations near the northern 


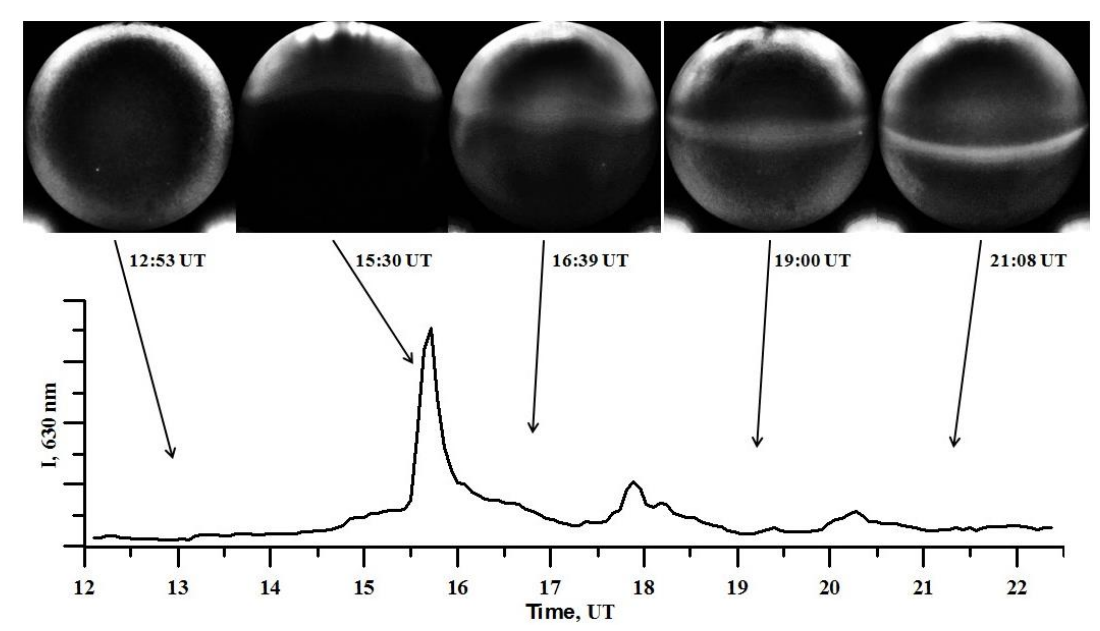

Figure 4. Images in the $630.0 \mathrm{~nm}$ emission captured by the all-sky camera KEO at 12:53, 15:30, 16:39, 19:00, and 21:08 UT (top) versus the $630.0 \mathrm{~nm}$ emission dynamics obtained by the patrol spectrograph (bottom)

horizon, airglow spots varying in shape are continuously recorded (an image second from the left in Figure 4), which are probably a manifestation of ordinary auroras.

The second layer of airglow, varying in shape (sometimes with a wavy equatorial boundary) and intensity, in the near-zenith region takes on a form of arc resembling the known SAR arcs [Rees, Roble, 1975], which, slowly moving equatorward, becomes more pronounced (Figure 4). In some periods, we can identify the appearance of the second, less weak arc, located to the north of the main arc (Figure 4, the first right image).

The detected arc moves to the south with an average velocity of $\sim 20 \mathrm{~m} / \mathrm{s}$ (calculated for an emission height of $\sim 400 \mathrm{~km}$ ). The movement of the arc in latitude correlates well with $D s t$ variations. The velocity of displacement and size of this arc match the parameters of SAR arcs reported in [Ievenko, Alekseev, 2004].

The interpretation of the images, presented in Figure 4 , as a SAR-arc phenomenon is supported by the fact that during this magnetic storm the subauroral optical station Maimaga in Yakutia $\left(63^{\circ} \mathrm{N}, 129.5^{\circ} \mathrm{E}\right)$ in the evening MLT sector also recorded an intense SAR arc [Ievenko, Parnikov, 2017].

The keogram for 15:00-15:30 UT (Figure 3) also exhibits a structure moving from smaller to larger angular heights and corresponding to times of beginning of the formation of the SAR arc as derived from data acquired with the all-sky camera (see, e.g., the image second from the left in Figure 4).

According to the classification [Rassoul et al., 1993], SAR arcs are mid-latitude auroras. It is now established that SAR arcs along magnetic field lines are adjacent to the region of interaction between hot ring current particles and cold external plasmasphere and, most likely, "represent the radial gradient of cold plasma density, where plasmospheric electrons are heated by energetic ring current particles" [Ievenko, Alekseev, 2004]. It should be kept in mind that SAR arcs are often associated with the projection of the plasmopause and respectively with the equatorial wall of the main ionospheric trough (MIT) [Khorosheva, 1987]. It is believed that a direct source of the $630.0 \mathrm{~nm}$ emission (the ${ }^{1} \mathrm{D}$ level) are electrons with energies of $<10 \mathrm{eV}$ [Rassoul et al., 1993].
Thus, the analysis of observations made with the allsky camera in the $630.0 \mathrm{~nm}$ emission shows that throughout the night near the northern horizon there were airglow spots with continuously varying shape, which are likely to be a manifestation of ordinary auroras.

Within the interval $\sim 16-21$ UT in the near-zenith region, there was a quite intense SAR arc. This may indicate the displacement of the MIT equatorial wall to the geomagnetic latitude of $\sim 47.9^{\circ} \mathrm{N}$ in the longitudinal sector of interest during this storm.

Interferometric observations in the $630.0 \mathrm{~nm}$ emission

Figure 5 presents the results of measurements of the $630.0 \mathrm{~nm}$ emission intensity and Doppler temperature $T_{630}$ in three directions - north, zenith, south - at zenith angles of $60^{\circ}, 0^{\circ}$, and $60^{\circ}$ respectively. The northerly viewing direction of FPI and spectrographs is virtually the same, hence the dynamics of the $630.0 \mathrm{~nm}$ emission intensity in this direction is also nearly identical (Figure 2). It should be noted (Figure 5) that there is a large intensity gradient simultaneously between the northerly direction and the direction to the zenith and south and almost the same average Doppler temperatures $T_{630} \sim 1450-1650 \mathrm{~K}$ after $15 \mathrm{UT}$ in these three directions. Heating of the upper atmosphere during geomagnetic storms and an increase in the Doppler temperature measured from the $630.0 \mathrm{~nm}$ emission are well known [Truttse, 1973; Earle et al., 2013]. Among possible causes of the increase in the temperature of the neutral atmosphere during geomagnetic storms are currently considered to be the Joule dissipation of currents in the auroral zone at heights of the lower thermosphere $(\sim 100-140 \mathrm{~km})$, followed by equatorward transport of the disturbed region due to additional circulation [Danilov, 2013; Earle et al., 2013]. In the subauroral ionosphere at heights above $200 \mathrm{~km}$ there may be frictional heating in a wide band of subauroral ion drifts westward near the plasmapause projection at F-layer heights. The drifts are most pronounced during substorms against the background of large-scale plasma convection [Zhang, 2017]. FPI data showing an increase in $T_{630}$ for all viewing directions from $\sim 1100-1150 \mathrm{~K}$ at the beginning of the measurements to $\sim 1450-1650 \mathrm{~K}$ at $15-16 \mathrm{UT}$ agree 

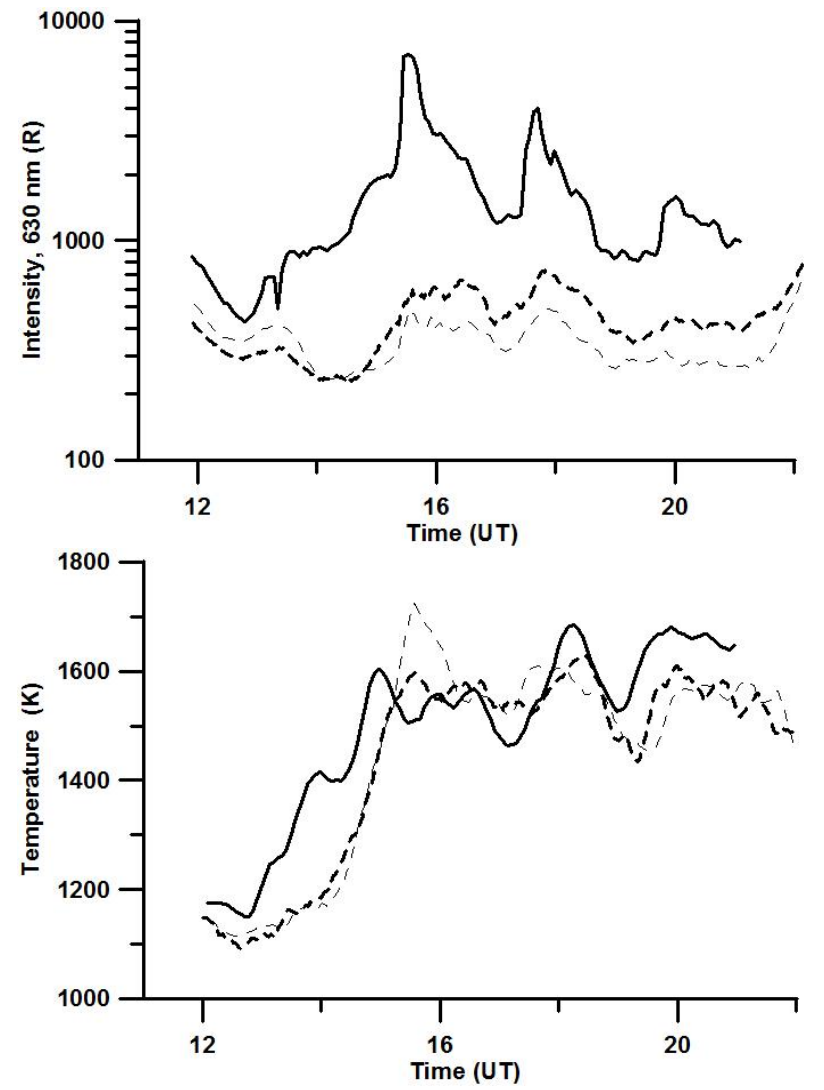

Figure 5. Measurements of $630.0 \mathrm{~nm}$ emission intensities and Doppler temperatures in three directions: thick solid lines - to the north; thick dashed lines - to the zenith; thin dashed lines - to the south

with experimental data and existing ideas about possible mechanisms of the neutral atmosphere heating at the F-layer heights during geomagnetic storms. However, the set of the obtained optical data, including temperature data, requires additional, more detailed studies of some features of the March 17, 2015 magnetic storm.

\section{CONCLUSIONS}

Nowadays there is no generally accepted concept of mid-latitude auroras in the literature. Some authors use the term low-latitude aurora, referring to auroral emissions observed during MS at geomagnetic latitudes of $\leq 50^{\circ}$. At the same time, other authors adopt the term mid-latitude aurora, using as distinctive features the presence of $\mathrm{N}_{2}^{+}$in the emission spectrum and the high ratio $r$ of the 630.0 and $557.7 \mathrm{~nm}$ emission intensities [Rassoul et al., 1993]. According to [Rassoul et al., 1993], MLA have some distinguishing features that allow us to separate them from ordinary auroras. Thus, according to the classification [Rassoul et al., 1993], MLA caused by electron precipitation are characterized by the ratio of the $630.0 \mathrm{~nm}$ red line intensity to the $557.7 \mathrm{~nm}$ green line intensity $r>10$ for SAR arcs and $1<r<10$ for type «d» MLA, whereas for ordinary auroras this value is usually within $\sim 0.2-1$ [Omholt, 1974]. Spectral measurements made with spectrographs at narrow angles above the horizon during the March 17, 2015 aurora of interest do not allow us to correctly determine $r$ because of possible latitudinal spacing of
630.0 and $557.7 \mathrm{~nm}$ emission layers. Nevertheless, the high $630.0 \mathrm{~nm}$ emission intensity, which is much higher than the $557.7 \mathrm{~nm}$ emission intensity, and the dominance of signals in the red channel over signals in the green channel as derived from data acquired with the color wide-angle camera at large angular heights indirectly indicate a rather high value of $r(>1)$. This may be an argument for identifying this aurora as mid-latitude.

Another feature of MLA noted in many works [Truttse, 1973; Rassoul et al., 1992; Mikhalev, 2001; Mikhalev et al., 2004] is the pronounced dependence of the main dominant emission of MLA at $630.0 \mathrm{~nm}$ on the degree of development of ring current during MS (by Dst). This is associated with some differences in formation mechanisms between mid-latitude aurora and aurora polaris. In our case, this dependence is broken by intense bursts of the 630 $\mathrm{nm}$ emission, which likely have substorm nature. This suggests the possibility of interpreting this aurora also as ordinary aurora polaris. Having regard to the above, we can assume that during the main phase of the March 17, 2015 GO simultaneously recorded MLA and ordinary auroras; therefore, the term mid-latitude aurora in the title of this article is rather conventional.

Thus, the results of the study of MLA, observed in the south of Eastern Siberia during St. Patrick's geomagnetic storm on March 17, 2015, allow us to draw a preliminary conclusion that this MLA is atypical of the longitudelatitude zone of interest. During the MS main phase, geophysical conditions might have been realized which allowed simultaneous recording of mid-latitude (type «d» and SAR arc) and auroral (type "a") forms of auroras.

Among the most interesting morphological features of the aurora, indicating, in particular, its atypical behavior, we can note the following:

- The maximum intensity of the dominant $630.0 \mathrm{~nm}$ emission ( 14 kR) during the March 17, 2015 magnetic storm enables us to assign these MLA to the extreme MLA observed in the vicinity of GO in 1991-2017. By the manifestation in the $630.0 \mathrm{~nm}$ emission the analyzed MLA is second only to the period of the superstorm on November 20, $2003(\sim 19 \mathrm{kR})$ and is superior to auroras during MS with stronger geomagnetic disturbances (by $D s t$ ).

- There is no dependence of the $630.0 \mathrm{~nm}$ emission on Dst at night, which is atypical of MLA previously observed at GO.

- There are intense bursts of the $630.0 \mathrm{~nm}$ emission with typical durations of $\sim 1 \mathrm{hr}$, which is more typical of substorm activity in subauroral and auroral latitudes.

- In the MLA spectrum, except for the dominant auroral 557.7 and $630.0 \mathrm{~nm}$ emissions also typical of midlatitude airglow, we detected the $520 \mathrm{~nm}$ [NI] emission and the $586.7 \mathrm{~nm} \mathrm{~N}_{2}^{+}$.

- Referring to interferometric observations in the $630.0 \mathrm{~nm}$ emission for $\sim 3 \mathrm{hr}$ there was an increase in the Doppler atomic oxygen temperature from 1100-1150 to $\sim 1450-1650 \mathrm{~K}$.

This work was performed using data from the optical complex included in CUC "Angara", http://ckp-rf.ru/ckp/ 3056. The work was performed with budgetary funding of Basic Research program II.16 and with support from RAS Presidium program No. 56 "Fundamentals of innovative national security technologies". 


\section{REFERENCES}

Beletsky A.B., Tashchilin M.A., Mikhalev A.V., Tatarnikov A.V. Spectral measurements of eigen emission of the night atmosphere with Shamrock SR-303i spectrograph. Sovremennye problemy distantsionnogo zondirovaniya Zemli iz kosmosa [Current Problems in Remote Sensing of the Earth From Space]. 2016, vol. 13, iss. 3, pp. 192-197. (In Russian).

Danilov A.D. Response of the F region to geomagnetic disturbances (Review). Geliogeofizicheskie issledovaniya [Heliogeophysical Res.]. 2013, vol. 5, pp. 1-33. (In Russian).

Earle G.D., Davidson R.L., Heelis R.A., Coley W.R., Weimer D.R., Makela J.J., Fisher D.J., Gerrard A.J., Meriwether J. Low latitude thermospheric responses to magnetic storms. $J$. Geophys. Res.: Space Phys. 2013, vol. 118, pp. 3866-3876. DOI: $10.1002 /$ jgra. 50212.

Gonzalez W.D., Tsurutani B.T., Alicia L. Clúa de Gonzalez. Interplanetary origin of geomagnetic storms. Space Sci. Rev. 1999, vol. 88, iss. 3-4, pp. 529-562.

Harding B.J., Gehrels T.W., Makela J.J. Nonlinear regression method for estimating neutral wind and temperature from Fabry-Perot interferometer data. Appl. Opt. 2014, vol. 53, pp. 666-673. DOI: 10.1364/AO.53.000666.

Ievenko I.B., Alekseev V.N. Substorm and storm effect on SAR arc dymamics. Statistical analysis. Geomagnetizm i aeronomiya [Geomagnetism and Aeronomy]. 2004, vol. 44, no. 5 , pp. 643-654. (In Russian).

Ievenko I.B., Parnikov S.G. Comparison of the overlap region of energetic plasma and a plasmapause by the Van Allen Probe data with the SAR arcs ground observations during storm and substorm. Solar-Terrestrial Relations and Physics of Earthquake Precursors. VIII International Conference, September 25-29, 2017, Paratunka, Kamchatskii krai: Abstracts. 2017, pp. 75-76.

Kamide Y., Kusano K. No major solar flares but the largest geomagnetic storm in the present solar cycle. Space Weather. 2015, vol. 13, pp. 365-367. DOI: 10.1002/2015SW001213.

Khorosheva O.V. Magnetospheric disturbances and dynamics of ionospheric electrojets, auroras, and plasmapause. Geomagnetizm i aeronomiya [Geomagnetism and Aeronomy]. 1987, vol. XXVII, no. 5, pp. 804-811. (In Russian).

Krakovetsky Yu.K., Loisha V.A., Popov L.N. Chronology of auroras for last millennium. Solnechnye dannye [Solar Data]. 1989, no. 5, pp. 110-115. (In Russian).

Mikhalev A.V. Some particulars in observation of midlatitude airglows and disturbances of the upper atmosphere emissions during magnetic storms in the Eastern Siberia region. Optika atmosfery $i$ okeana [Atmospheric and Oceanic Optics]. 2001, vol. 14, no. 10, pp. 970-973. (In Russian).

Mikhalev A.V. Seasonal and interannual variations in the [OI] $630 \mathrm{~nm}$ atmospheric emission as derived from observations over Eastern Siberia in 2011-2017. Solar-Terr. Phys. 2018, vol. 4, iss. 2, pp. 58-62, DOI: 10.12737/stp-42201809.

Mikhalev A.V., Beletsky A.B., Kostyleva N.V., Chernigovskaya M.A. Mid-latitude airglows in the southeast Siberia during strong magnetic storms on October 29-31 and November 20-21, 2003. Kosmicheskie issledovaniya [Cosmic Res.]. 2004, vol. 42, no. 6, pp. 616-621. (In Russian).

Mikhalev A.V., Beletsky A.B., Kostyleva N.V., Chernigovskaya M.A. Characteristics of mid-latitude airglows during strong magnetic storms in the current solar cycle. Optika atmosfery i okeana [Atmospheric and Oceanic Optics]. 2005, vol. 18, no. 01-02, pp. 155-159. (In Russian).

Mikhalev A.V., Podlesny S.V., Stoeva P.V. Night airglow in RGB mode. Solar-Terr. Phys. 2016, vol. 2, iss. 3, pp. 106-114. DOI: $10.12737 / 22289$.

Omholt A. Polyarnye siyaniya [Auroras]. Moscow, Mir Publ., 1974, 246 p. (In Russian).

Podlesny S.V., Mikhalev A.V. Spectrophotometry of midlatitude airglows observed in the Eastern Siberia region during magnetic storms on February 27, 2014 and March 17, 2015. Mezhdunarodnaya Baikalskaya molodezhnaya nauchnaya shkola po fundamentalnoi fizike. XIV Konferentsiya molodykh uchenykh "Vzaimodeistvie polei i izlucheniya s veshchestvom [Young Scientists' International School on Fundamental Physics. XV Young Scientists' Conference "Interaction of Fields and Radiation with Matter"]. Irkutsk, 2015, pp. 175-177. (In Russian).

Rassoul H.K., Rochrbaugh R.P., Tinsley B.A. Low-latitude particle precipitation and associated local magnetic disturbance. J. Geophys. Res. 1992, vol. 97, no. A4. pp. 4041-4052.

Rassoul H.K., Rohrbaugh R.P., Tinsley B.A., Slater D.W. Spectrometric and photometric observations of low-latitude aurorae. J. Geophys. Res. 1993, vol. 98, no. A5, pp. 7695-7709.

Rees M.H., Roble R.G. Observations and theory of the formation of stable auroral red arcs. Res. Geophys. 1975, vol. 13, no. 1, pp. 201-242.

Shiokawa K., Otsuka Y., Oyama S., Nozawa S., Satoh M., Katoh Y., Hamaguchi Y., Yamamoto Y., Meriwether J. Development of low-cost sky-scanning Fabry-Perot interferometers for airglow and auroral studies. Earth Planet Space. 2012, vol. 63, iss. 11, pp. 1033-1046. DOI: 10.5047/eps.2012.05.004.

Truttse Yu.L. Upper atmosphere during geomagnetic disturbances. Polyarnye siyaniya i svecheniya nochnogo neba [Auroras and Night Airglows]. 1973, vol. 20, pp. 5-22. (In Russian).

Vasilyev R.V., Artamonov M.F. Beletsky A.B., Zherebtsov G.A., Medvedeva I.V., Mikhalev A.V., Syrenova T.E. Registering upper atmosphere parameters in East Siberia with Fabry — Perot Interferometer KEO Scientific "Arinae" Solar-Terr. Phys. 2017, vol. 3, iss. 3, pp. 61-75. DOI: $10.12737 /$ stp-33201707.

Zhang Shunrong. Ionospheric observational campaign study of geospace storms: a scenario for strong ionosphere and thermosphere coupling during the 2015 St Patrick's day storm. Second VarSITI General Symposium (VarSITI-2017). Meeting place: Marriot Courtyard City Center, Irkutsk, July 10-15, 2017. VarSITI Abstracts, p. 104.

URL: http://wdc.kugi.kyoto-u.ac.jp/dst_realtime (accessed May 12, 2018). 2018).

URL: http://atmos.iszf.irk.ru/ru/data/spectr (accessed May 12,

URL: http://atmos.iszf.irk.ru/ru/data/color (accessed May 12, 2018).

URL: http://atmos.iszf.irk.ru/ru/data/keo (accessed May 12, 2018).

URL: http://ckp-rf.ru/ckp/3056 (accessed May 12, 2018).

How to cite this article

Mikhalev A.V., Beletsky A.B., Vasilyev R.V., Zherebtsov G.A., Podlesny S.V., Tashchilin M.A., Artamonov M.F. Spectral and photometric characteristics of mid-latitude auroras during the magnetic storm of March 17, 2015. Solar-Terrestrial Physics. 2018. Vol. 4. Iss. 4. P. 42-47. DOI: $10.12737 /$ stp-44201806. 